\title{
ORDENAMENTO AGROAMBIENTAL DAS ÁREAS DE AFLORAMENTO DO AQÜÍFERO GUARANI: ESTUDO DE CASO NOS ESTADOS DE \\ SÃO PAULO, GOIÁS E DE MATO GROSSO
}

\begin{abstract}
O presente trabalho procurou mostrar que a organização do espaço territorial agrícola, em forma de ordenamento agroambiental, constitui instrumento de grande relevância nos estudos ambientais, sobretudo em áreas de grande vulnerabilidade natural ou de alta fragilidade, como as áreas de afloramento ou recarga direta de aqüíferos sedimentares, a exemplo do Aqüífero Guarani. Para esse estudo foram adotadas duas áreas representativas da recarga direta desse aqüífero, sendo a primeira caracterizada pela microbacia do córrego Espraiado, localizada na região de Ribeirão Preto/SP (Domínio Pedomorfoagroclimático do Planalto Médio Paulista) e a segunda pela depressão ou nascentes do rio Araguaia (Domínio Pedomorfoagroclimático homônimo), localizada em parte dos estados de Goiás (margem direita) e de Mato Grosso (margem esquerda). Os procedimentos consistiram na integração de informações sobre as áreas em questão, relacionadas à geologia (material de origem do solo), classificação dos solos, vulnerabilidade natural, riscos de contaminação do lençol freático, capacidade de uso dos solos, cobertura vegetal em consonância com o Código Florestal Brasileiro e, ainda, Boas Práticas Agrícolas (BPA).
\end{abstract}

PALAVRAS-CHAVE: VULNERABILIDADE NATURAL; CAPACIDADE DE USO DAS TERRAS; BOAS PRÁTICAS AGRÍCOLAS; USO SUSTENTÁVEL; ÁREAS DE RECARGA.

* Geólogo, Doutor em Solos, Pesquisador da Embrapa Meio Ambiente, Jaguariúna, SP (e-mail: gomes@cnpma.embrapa.br).

** Engenheiro Agrônomo, Doutor em Planejamento Agroambiental, Pesquisador da Embrapa Meio Ambiente, Jaguariúna, SP (e-mail: lauro@cnpma.embrapa.br). 


\section{INTRODUÇÃO}

Com o surgimento de demanda sobre o uso sustentável das áreas de recarga direta do Aqüífero Guarani, a partir de proposta de agenda básica apresentada em Curitiba em 1996 (ROCHA, 1996), a Embrapa Meio Ambiente propôs, em 1999, um trabalho com abrangência para todas as áreas de recarga em território brasileiro. Esse trabalho, com duração de três anos, aliado a outros posteriores (EMBRAPA, 2002; EMBRAPA, 2006a; EMBRAPA, 2006b), possibilitaram o levantamento de informações sobre geologia, solos, relevo, vegetação, clima e uso agrícola em escalas de maior detalhe (1:50.000 e 1:25.000). A integração dessas informações permitiu a definição das áreas de recarga direta em Domínios Pedomorfoagroclimáticos (GOMES et al., 2006), importantes nos estudos para proposição do ordenamento agroambiental.

\section{MATERIAL E MÉTODOS}

O método proposto possibilita a integração dos Planos de Informação (PI) de geologia, solos, relevo, vegetação, clima e de uso agrícola atual, considerando áreas selecionadas a partir do conhecimento sobre os domínios pedomorfoagroclimáticos (GOMES et al., 2006). As atividades agrícolas indicam previamente a carga potencial de entrada de insumos ou agroquímicos, aliada ao manejo do solo. Assim, podem ser definidas as áreas que oferecem maiores riscos, tanto em relação à contaminação do lençol freático quanto em relação aos processos erosivos (Figura 1). Informações adicionais, tais como precipitação pluviométrica e tipo de solo, permitem a caracterização de risco em escala genérica de pouco detalhe, a exemplo do que foi efetuado para toda a área de recarga direta em território brasileiro (EMBRAPA, 2002). Essa caracterização fundamentou-se em três níveis - baixo, médio e alto, conforme o tipo de atividade agrícola predominante em cada um dos domínios estabelecidos para essas áreas.

Ao se considerar escala de maior detalhe (1:25.000 e 1:50.000), o acréscimo de informações torna-se fundamental, como se observa na Tabela 1, em que foram inseridos parâmetros como condutividade hidráulica e profundidade do nível d'água.

O objetivo principal deste trabalho foi desenvolver proposta de ordenamento agroambiental específica para as áreas de recarga direta ou de afloramento do Aqüífero Guarani em território brasileiro, como subsídio para proposta de gestão ambiental, apoiada nas técnicas de Boas Práticas Agrícolas. Para tanto, foram selecionadas duas áreas a partir das cinco descritas acima: a Microbacia do Córrego do Espraiado, município de Ribeirão Preto/SP, no Domínio do Planalto Médio Paulista e a região das Nascentes do rio Araguaia no Domínio da Depressão do Araguaia.

A partir da caracterização dos riscos por domínio, contidas na Figura 1, foram selecionadas cinco áreas críticas (worst case) distribuídas em cinco estados, conforme a seguinte descrição:

a) Microbacia do Córrego do Espraiado, região de Ribeirão Preto/SP - Domínio do Planalto Médio Paulista;

b) Nascentes do rio Araguaia/Microbacia dos Córregos Cabeceira Alta e Buracão, município de Mineiros/GO - Domínio da Depressão ou Nascentes do rio Araguaia;

c) Afluentes da margem direita do rio Taquarí, município de Alcinópolis/MS - Domínio do Médio/Alto Taquarí e Coxim;

d) Nascentes do rio Ivaí, município de Cândido de Abreu/PR - Domínio do Segundo Planalto Paranaense

e) Arroio Jacaguá, margem esquerda do rio Ibicuí, região de Alegrete/RS - Domínio da Campanha. Posteriormente, foi identificada mais uma área na região de Lages/Ponte Alta - SC, envolvendo as nascentes dos rios Caveiras e dos Cachorros, no Domínio definido como Planalto Médio Catarinense, que assim servirão de estudos de caso e de suporte para proposta de gestão, fundamentada nos princípios de sustentabilidade. 


\section{FIGURA 1 - MAPA DE RISCOS POTENCIAIS DE CONTAMINAÇÃO DA ÁGUA SUBTERRÂNEA DO AQÜÍFERO GUARANI POR DOMÍNIO PEDOMORFOAGROCLIMÁTICO (ESCALA 1:5.000.000)}

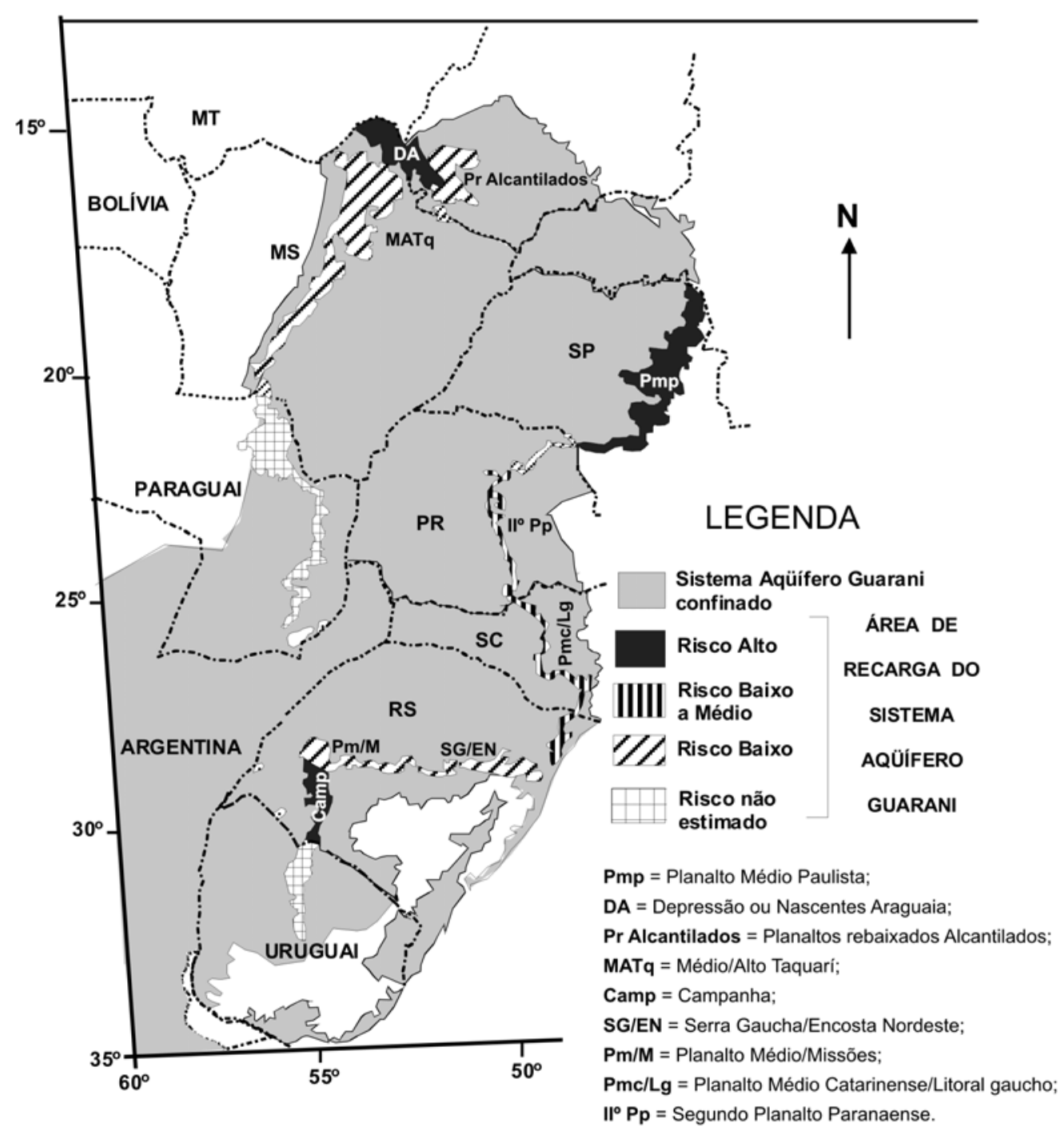

Mapa obtido da base proposta por ARAÚJO, FRANÇA e POTTER (1995).

\subsection{LEVANTAMENTO DE INFORMAÇÕES}

A seleção das duas microbacias, as quais serviram como áreas pilotos para estudo de caso e de suporte à elaboração do ordenamento agroambiental das áreas de recarga, foi realizada com base em dois critérios fundamentais: a) estar localizada em área de recarga do Aqüífero Guarani e b) apresentar predominância da atividade agrícola, preferencialmente intensiva, com alta entrada de insumos.

O levantamento das características fisiográficas das áreas selecionadas foi realizado por meio do material cartográfico e bibliográfico já existente. As informações climáticas, pluviosidade e temperatura, foram obtidas a partir de dados já compilados pelo Instituto Agronômico de Campinas (IAC) para o Estado de São Paulo e junto aos levantamentos realizados pela Agência Rural de Goiás, Fundação Emas e Oréades - Núcleo de Geoprocessamento, instituições localizadas na região das nascentes do Araguaia. 

GUARANI, EM QUATRO ESTADOS BRASILEIROS, CONSIDERANDO A PRESENÇA DE CINCO HERBICIDAS

\begin{tabular}{|c|c|c|c|c|c|c|c|c|c|c|}
\hline \multirow[b]{2}{*}{ 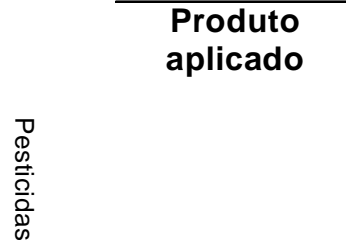 } & \multirow{2}{*}{$\begin{array}{c}\text { Quantida } \\
\text { de } \\
\text { (L/ha) }\end{array}$} & \multirow{2}{*}{$\begin{array}{c}\text { Características } \\
\text { do produto }\end{array}$} & \multirow[t]{2}{*}{ Cultura } & \multirow[t]{2}{*}{ Estado } & \multirow{2}{*}{$\begin{array}{c}\text { Área } \\
\text { (ha) }\end{array}$} & \multirow{2}{*}{$\begin{array}{c}\text { Precipitação } \\
\text { Média* }^{*} \\
\text { (mm/ano) }\end{array}$} & \multicolumn{3}{|c|}{ Vulnerabilidade } & \multirow{2}{*}{$\begin{array}{c}\text { Risco } \\
\text { Potencial }^{1} \text { de } \\
\text { contaminação da água }_{\text {subterrânea }}\end{array}$} \\
\hline & & & & & & & \begin{tabular}{|l|}
$\begin{array}{l}\text { Condutivi- } \\
\text { dade } \\
\text { hidráulica** } \\
(\mathrm{cm} / \mathrm{h})\end{array}$
\end{tabular} & $\begin{array}{l}\text { Nível } \\
\text { d'água*** }^{\text {NA }} \\
\text { (m) }\end{array}$ & índice & \\
\hline Imazetapir & 1,0 & $\begin{array}{c}\text { Koc }=10 ;(\mathrm{T})^{1 / 2}= \\
90 \text { dias }\end{array}$ & Soja & Goiás & 4.000 & 1.863 & Alta & $\begin{array}{c}<10 \\
10-20 \\
>20 \\
\end{array}$ & $\begin{array}{l}\text { ALTO alto }(\mathrm{Aa}) \\
\text { ALTO baixo }(\mathrm{Ab}) \\
\text { MÉDIO alto }(\mathrm{Ma})\end{array}$ & $\begin{array}{c}\text { Alto } \\
\text { Médio/Alto } \\
\text { Médio }\end{array}$ \\
\hline \multirow{3}{*}{ Atrazina } & \multirow{3}{*}{2,0} & \multirow[t]{3}{*}{$\begin{array}{l}\text { Koc=100; }(T)^{1 / 2} \\
\text { vida }=60 \text { dias }\end{array}$} & Milho & Goiás & 10.000 & 1.863 & Média/alta & $\begin{array}{c}<10 \\
10-20 \\
>20\end{array}$ & $\begin{array}{l}\text { ALTO alto (Aa) } \\
\text { ALTO baixo }(\mathrm{Ab}) \\
\text { MÉDIO alto }(\mathrm{Ma})\end{array}$ & $\begin{array}{l}\text { Médio } \\
\text { Médio/baixo } \\
\text { Baixo }\end{array}$ \\
\hline & & & Milho & $\begin{array}{c}\text { Mato } \\
\text { Grosso }\end{array}$ & 5.800 & 2.130 & Média/alta & $\begin{array}{c}<10- \\
10-20 \\
>20\end{array}$ & $\begin{array}{l}\text { ALTO alto }(\mathrm{Aa}) \\
\text { ALTO baixo }(\mathrm{Ab}) \\
\text { MÉDIO alto (Ma) }\end{array}$ & $\begin{array}{l}\text { Médio/Alto } \\
\text { Médio } \\
\text { Baixo }\end{array}$ \\
\hline & & & Milho & $\begin{array}{l}\text { Mato } \\
\text { Grosso } \\
\text { do Sul } \\
\end{array}$ & 2.600 & 1.460 & Alta & $\begin{array}{c}<10 \\
10-20 \\
>20 \\
\end{array}$ & $\begin{array}{l}\text { ALTO alto }(\mathrm{Aa}) \\
\text { ALTO baixo }(\mathrm{Ab}) \\
\text { MÉDIO alto (Ma) }\end{array}$ & $\begin{array}{c}\text { Médio } \\
\text { Médio/baixo } \\
\text { Baixo } \\
\end{array}$ \\
\hline Simazina & 2,0 & $\begin{array}{l}\text { Koc= 130; }(\mathrm{T}) \\
1 / 2 \text { vida curta } 60 \\
\text { dias }\end{array}$ & Milho & Goiás & 10.000 & 1.863 & Alta & $\begin{array}{c}<10 \\
10-20 \\
>20 \\
\end{array}$ & $\begin{array}{l}\text { ALTO alto }(\mathrm{Aa}) \\
\text { ALTO baixo }(\mathrm{Ab}) \\
\text { MÉDIO alto (Ma) }\end{array}$ & $\begin{array}{c}\text { Médio } \\
\text { Médio/Baixo } \\
\text { Baixo } \\
\end{array}$ \\
\hline Tebutiuron & 1,3 & $\begin{array}{c}\mathrm{Koc}=80 ;(\mathrm{T})^{1 / 2} 2 \\
\text { vida }=360 \text { dias }\end{array}$ & $\begin{array}{l}\text { Cana-de- } \\
\text { açúcar }\end{array}$ & $\begin{array}{l}\text { São } \\
\text { Paulo }\end{array}$ & 980.000 & 1.600 & Alta & $\begin{array}{c}<10 \\
10-20 \\
>20 \\
\end{array}$ & $\begin{array}{l}\text { ALTO alto }(\mathrm{Aa}) \\
\text { ALTO baixo }(\mathrm{Ab}) \\
\text { MÉDIO alto (Ma) }\end{array}$ & $\begin{array}{c}\text { Alto } \\
\text { Médio/Alto } \\
\text { Médio } \\
\end{array}$ \\
\hline Hexazinona & 2,3 & $\begin{array}{l}\text { Koc }=54 ;(T)^{1 / 2} \\
\text { vida }=90 \text { dias }\end{array}$ & $\begin{array}{l}\text { Cana-de- } \\
\text { açúcar }\end{array}$ & $\begin{array}{c}\text { São } \\
\text { Paulo }\end{array}$ & 980.000 & 1.600 & Alta & $\begin{array}{c}<10 \\
10-20 \\
>20 \\
\end{array}$ & $\begin{array}{l}\text { ALTO alto }(\mathrm{Aa}) \\
\text { ALTO baixo }(\mathrm{Ab}) \\
\text { MÉDIO alto }(\mathrm{Ma})\end{array}$ & $\begin{array}{c}\text { Alto } \\
\text { Médio/Alto } \\
\text { Médio }\end{array}$ \\
\hline
\end{tabular}

*Média dos últimos 5 anos; **classificada em alta ( $\geq 25 \mathrm{~cm} / \mathrm{h})$; média (12,5 a $25 \mathrm{~cm} / \mathrm{h})$ e baixa $(2,5 \mathrm{a} 12,5 \mathrm{~cm} / \mathrm{h})$. Adaptado de SMITH e BROWING (1946) por KRAMER (1969). ${ }_{* * *} \mathrm{NA} \leq 010 \mathrm{~m}$ ( vulnerabilidade do tipo alto-alto); NA 10-20 m (alto-baixo); NA $\geq 20$ (médio -alto) conforme SÃO PAULO, 1997.

1 - Define-se aqui risco potencial como sendo o risco estimado, em função da integração das informações relativas aos produtos aplicados com suas respectivas quantidades (carga contaminante estimada) com aquelas relacionadas à vulnerabilidade natural. 
O levantamento do uso agrícola das áreas pilotos foi realizado a partir de imagens de satélite Landsat TM, utilizando-se técnicas de processamento digital de imagem (correções radiométrica e geométrica) e identificação e classificação dos diferentes alvos agrícolas com confirmação em campo.

Este trabalho teve como suporte básico a utilização das técnicas de geoprocessamento para o armazenamento, manipulação e integração de dados ambientais referenciados espacialmente. A elaboração dos Planos de Informação ocorreu a partir das informações citadas acima, utilizando-se técnicas de captura digital e de geoprocessamento para montagem do banco de dados. Neste estudo, a entrada dos dados foi realizada mediante mesa digitalizadora, utilizando-se o software de digitalização AutoCAD 2006 (MATSUMOTO, 2005). Para o controle da digitalização adotou-se o Quadrado Médio do Resíduo (QMR) como medida da precisão, visando garantir a qualidade dos dados no Sistema de Informação Geográfica (SIG). Os mapas foram digitalizados na projeção cartográfica Universal Transversa de Mercator (UTM).

Para o levantamento dos agrotóxicos mais utilizados aplicou-se um questionário junto ao(s) proprietário(s) rurais, técnicos e revendedores, buscando informações quanto aos produtos aplicados (dose, número médio de aplicações e histórico das aplicações). Foram também levantadas informações desses agrotóxicos, a partir de dados da literatura, referentes ao princípio ativo e suas características físico-químicas. Essas informações foram utilizadas, posteriormente, no cálculo do índice de GUS (GUSTAFSON, 1989).

\subsection{AVALIAÇÃO DA VULNERABILIDADE NATURAL}

O levantamento da profundidade do lençol freático nas áreas pilotos foi realizado por meio de sondagem elétrica, com o uso do método da eletrorresistividade (IPT, 1994), específico para a microbacia do córrego do Espraiado e por catalogação de poços existentes no caso das nascentes do rio Araguaia (EMBRAPA, 2006a). Foram adotados como referências pontos de amostragem georreferenciados, cotas altimétricas e locais que representam mudanças de expressão no relevo da área, conforme proposição de FERNANDES (1984).

O método de avaliação da vulnerabilidade natural das áreas objeto deste estudo seguiu as proposições de FOSTER e HIRATA (1993), baseando-se na exposição do lençol freático a uma carga contaminante que passa a ser função da: a) profundidade do solo, que influencia a acessibilidade da carga contaminante à zona saturada e b) capacidade de atenuação da carga contaminante, controlada principalmente pelos parâmetros geológicos e de cobertura de solos. Houve também a inclusão de dados de condutividade hidráulica (integração de dados de textura, estrutura e profundidade do lençol freático) e declividade do solo, como também da taxa média de precipitação anual, que fornece indicativos do potencial do veículo condutor (água) para movimentar a suposta carga contaminante (GOMES et al., 1996; GOMES, SPADOTTO e PESSOA, 2002; GOMES, FILIZOLA e SPADOTTO 2002).

A profundidade do solo foi avaliada por meio de tradagens. Análises de condutividade hidráulica foram realizadas em laboratório, adotando-se o método da coluna de solo $(20 \mathrm{~cm})$ saturada em água e com lâmina constante (carga hidráulica) de 2,0 cm (EMBRAPA, 1997). Informações pré-existentes, tais como mapas geológicos, geofísicos e geomorfológicos subsidiaram esses estudos.

A avaliação dos processos erosivos lineares (voçorocas e ravinas) nas áreas selecionadas ocorreu por fotointerpretação e análise de imagens de satélite, conforme procedimentos propostos pelo DAEE (SÃO PAULO, 1989) e IPT (1994).

\subsection{CAPACIDADE DE USO DAS TERRAS}

$\mathrm{Na}$ avaliação do potencial de uso das terras, os métodos adotados foram o sistema de classificação da capacidade de uso da terra (LESPCH et al., 1991) e o sistema de avaliação da aptidão agrícola das terras (RAMALHO FILHO, PERREIRA e BEEK, 1995), esse com adaptações conforme PEREIRA (2002). Nesses métodos foram utilizadas as informações de levantamento de solo (MIKLÓS e GOMES, 1996; EMBRAPA, 2006a; EMBRAPA, 2006b), bem como de classes de declividade 
e climáticas. Empregou-se o Sistema de Informação Geográfica (SIG) de forma a utilizar suas operações espaciais. A declividade foi obtida do mapa de curvas de nível, utilizando-se modelo de interpolação do próprio SIG e, posteriormente, separadas em classes. A determinação do balanço hídrico para as culturas predominantes, nas áreas estudadas, baseou-se no modelo proposto por FRANQUIN e FOREST (1984). Os resultados obtidos pelos dois métodos foram comparados, utilizando-se as técnicas de geoprocessamento.

Apesar do método de avaliação da aptidão agrícola contemplar três níveis de manejo, correspondentes aos níveis tecnológicos baixo, médio e alto ( $A, B$ e $C$ ), apenas os níveis $B$ e $C$ foram adotados devido ao padrão tecnológico médio e elevado na área de estudo.

Utilizando-se do plano de informação de ocupação e uso atual, obtido de imagens recentes (2007) do satélite Landsat TM das áreas pilotos, e confrontando-o com os mapas de capacidade de uso foram obtidos os mapas de conflito das respectivas áreas.

Foram utilizados os seguintes softwares do SIG: o Idrisi for Windows (EASTMAN, 2006) e o Spring do Instituto Nacional de Pesquisas Espaciais, esse último de domínio público (CÂMARA et al., 1996).

\subsection{ESTUDO DOSAGROTÓXICOS}

Avaliou-se o potencial de contaminação de água subterrânea pelos agrotóxicos por meio do método Groundwater Ubiquity Score (GUS), proposto por GUSTAFSON, 1989.

Foram desenvolvidos/ajustados métodos para a determinação dos agrotóxicos selecionados na matriz água, considerando nove pontos/poços de coleta na área das nascentes do rio Araguaia e sete pontos/poços na microbacia do córrego do Espraiado. Antes da análise instrumental foi necessária a execução das seguintes etapas: extração, remoção de interferentes (cleanup) e pré-concentração dos agrotóxicos da matriz, a fim de ajustar as concentrações do analito de interesse à sensibilidade do detector, bem como remover a maior parte dos interferentes. Assim foram testados diversos métodos de extração e pré-concentração para escolher aquele que fornecesse melhor recuperação e seletividade (cromatogramas relativamente livres de interferentes nos tempos de retenção dos compostos a serem analisados). Os extratos foram analisados por cromatografia em fase líquida de alta eficiência (CLAE) para compostos polares e instáveis termicamente, ou cromatografia em fase gasosa (CG) para compostos voláteis. Foram desenvolvidos e adaptados métodos da literatura (LYDON, ENGELKE e HELLING 1991; BOBELDIJK-PASTOROVA, 2000) para determinação de resíduos dos agrotóxicos nas matrizes de solo a fim de serem utilizados nas determinações dos seguintes parâmetros: coeficiente de adsorção do agrotóxico no solo, determinação da meia-vida ( $T^{1 / 2}$ ) e estudos de lixiviação.

\subsection{RISCO DE CONTAMINAÇÃO}

O simulador CMLS-94, "Chemical Movement in Layered Soils" (NOFZIGER e HORNSBY, 1994), foi utilizado nas áreas pilotos em função da: a) menor quantidade de dados de entrada para sua utilização em relação a outros simuladores, elaborados para o mesmo fim; b) facilidade de obtenção do software disponível na Internet; e c) qualidade das informações que disponibiliza como resultados (profundidade e quantidade de produto), que são fundamentais aos estudos de previsão de contaminação de águas subterrâneas.

Para efeito de simulações foram realizados cenários que permitem estimar a quantidade relativa de agrotóxico presente no solo, em qualquer instante de tempo, durante o período estipulado para a simulação (3 anos).

Os resultados obtidos indicaram para cada período simulado se os agrotóxicos iriam ou não atingir profundidades comprometedoras ao lençol subterrâneo.

Os resultados obtidos nas simulações foram inseridos como mais um Plano de Informação (PI) no SIG. Esse PI, com as simulações realizadas, mais os Planos de Informação de Profundidades dos Lençóis e de Uso das Terras foram integrados (operações de análise geográfica) de forma a se obter o mapa de risco de contaminação. 
A partir da informação referente à localização das áreas pilotos, representativas dos sistemas produtivos, foram identificados os pontos de coleta das amostras de água. As coletas corresponderam a nove amostras, retiradas a cada três meses, durante três anos (2004-2006) para a região das nascentes do rio Araguaia. Já para a microbacia do córrego do Espraiado, em Ribeirão Preto, as informações foram registradas com a mesma freqüência de coleta, diferindo da outra área apenas no número de pontos de amostragem de água que correspondeu a sete.

\subsection{ORDENAMENTO AGROAMBIENTAL}

A concepção do ordenamento agroambiental engloba a proposta de FIGUEIREDO et al. (2000) para o zoneamento agrícola/florestal e as do zoneamento ambiental proposto por RIBEIRO (1994) e pelo Ministério do Meio Ambiente (BRASIL, 1997). Essa integração requer base de informações fundamentadas em: a) levantamento das características fisiográficas e de uso agrícola das áreas a serem estudadas; b) avaliação da vulnerabilidade natural; c) classificação da capacidade de uso das terras e determinação de áreas de conflito; d) qualificação e quantificação dos agrotóxicos de maior risco para a água subterrânea; e) realização de estudos de risco de contaminação da água subterrânea; f) identificação do perfil socioeconômico e cultural dos produtores localizados nas áreas de estudo.

A Figura 2 exibe o diagrama com a proposição metodológica do ordenamento agroambiental, considerando uma área em São Paulo e outra nas nascentes do rio Araguaia, envolvendo os estados de Goiás e Mato Grosso.

\section{FIGURA 2 - DIAGRAMA DOS PLANOS DE EXECUÇÃO PARA OBTENÇÃO DO ORDENAMENTO AGROAMBIENTAL}

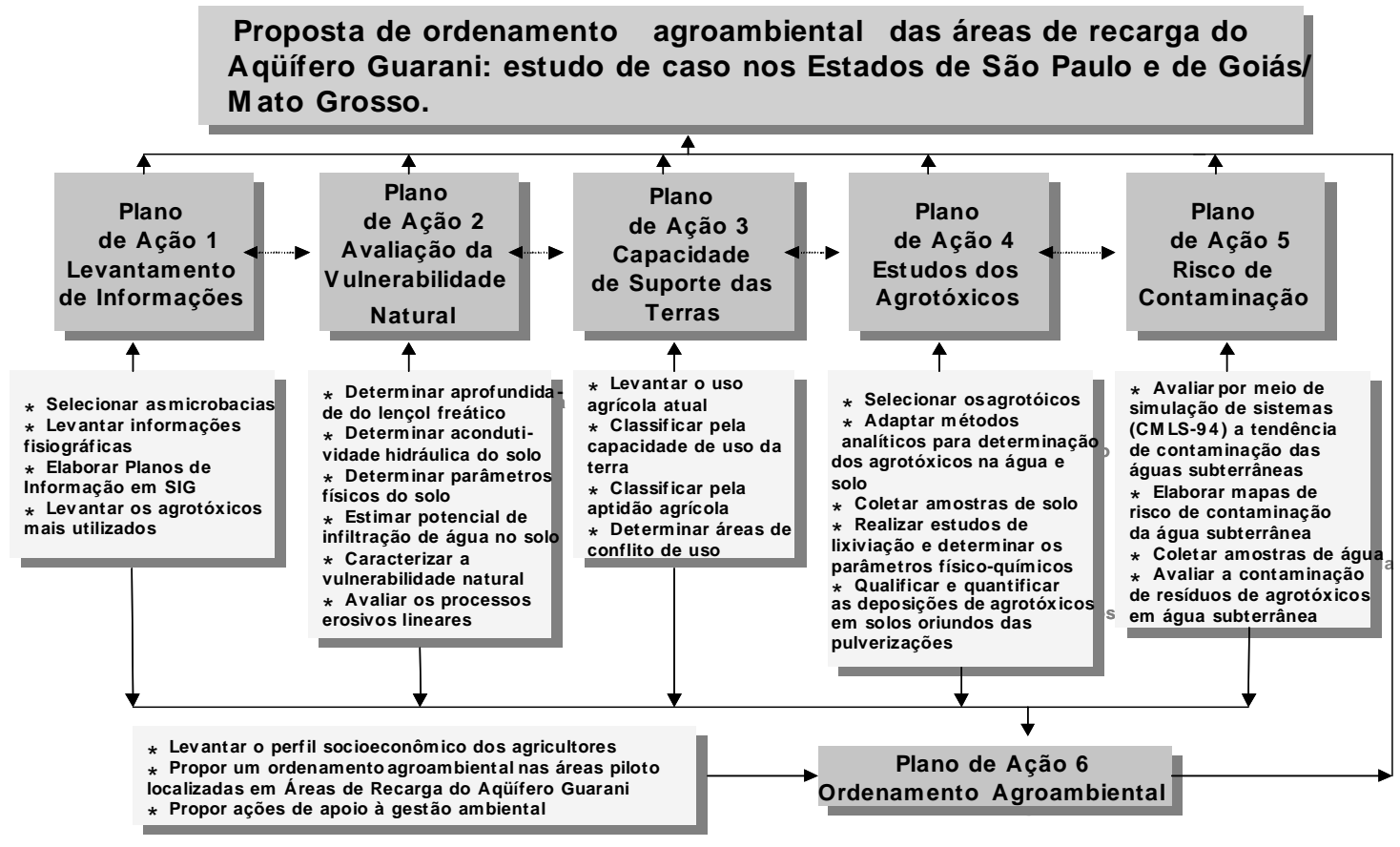

\section{RESULTADOS E DISCUSSÃO}

Os resultados obtidos estão expressos nas Tabelas 2 e 3 e nas Figuras 3 e 4, respectivamente, que exibem o Ordenamento Agroambiental das áreas de São Paulo (microbacia do córrego do Espraiado) e de Goiás/Mato Grosso (nascentes do rio Araguaia). 


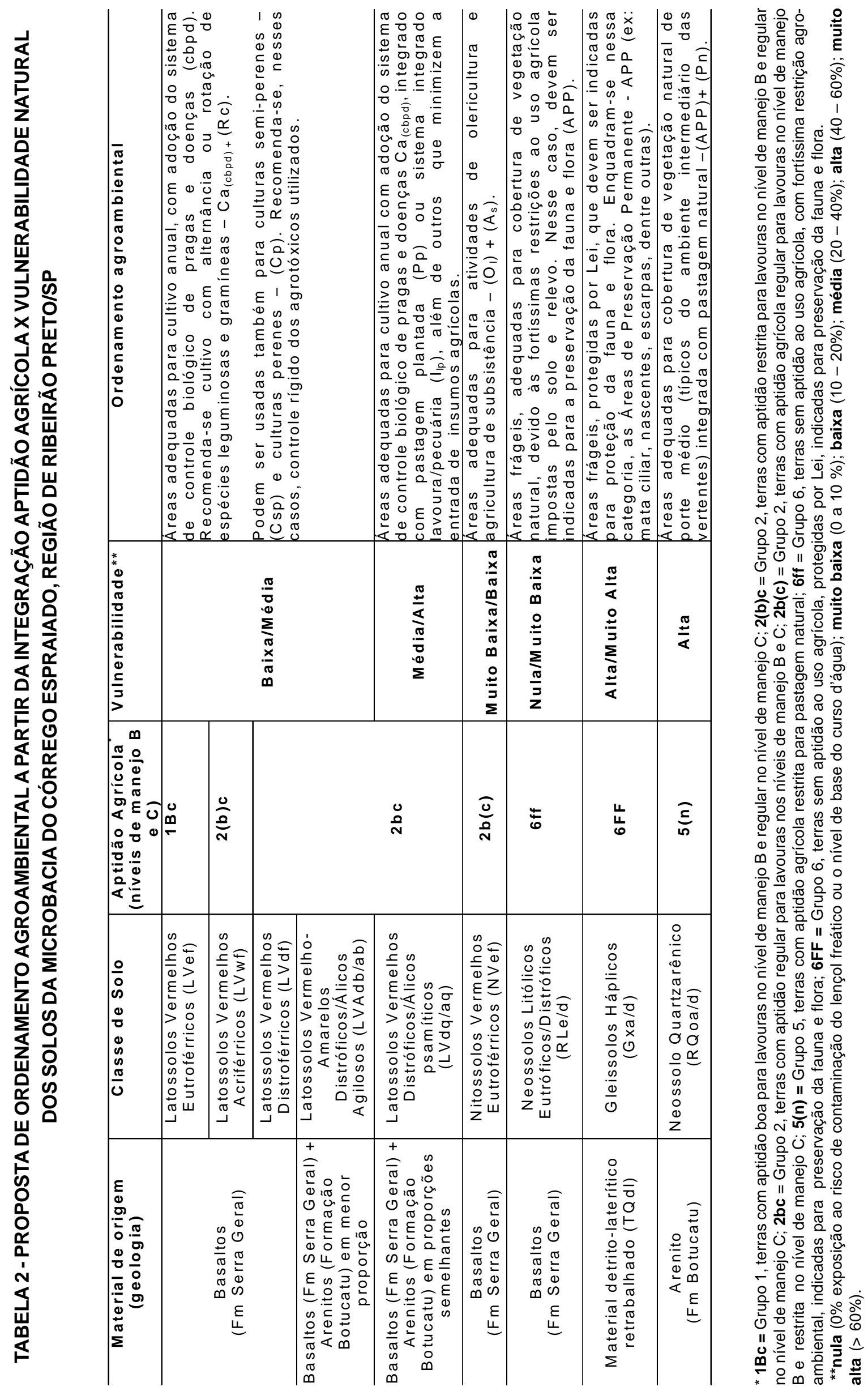




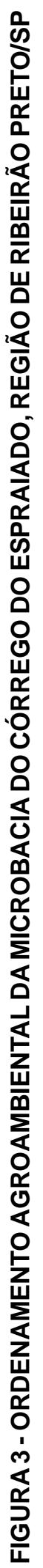

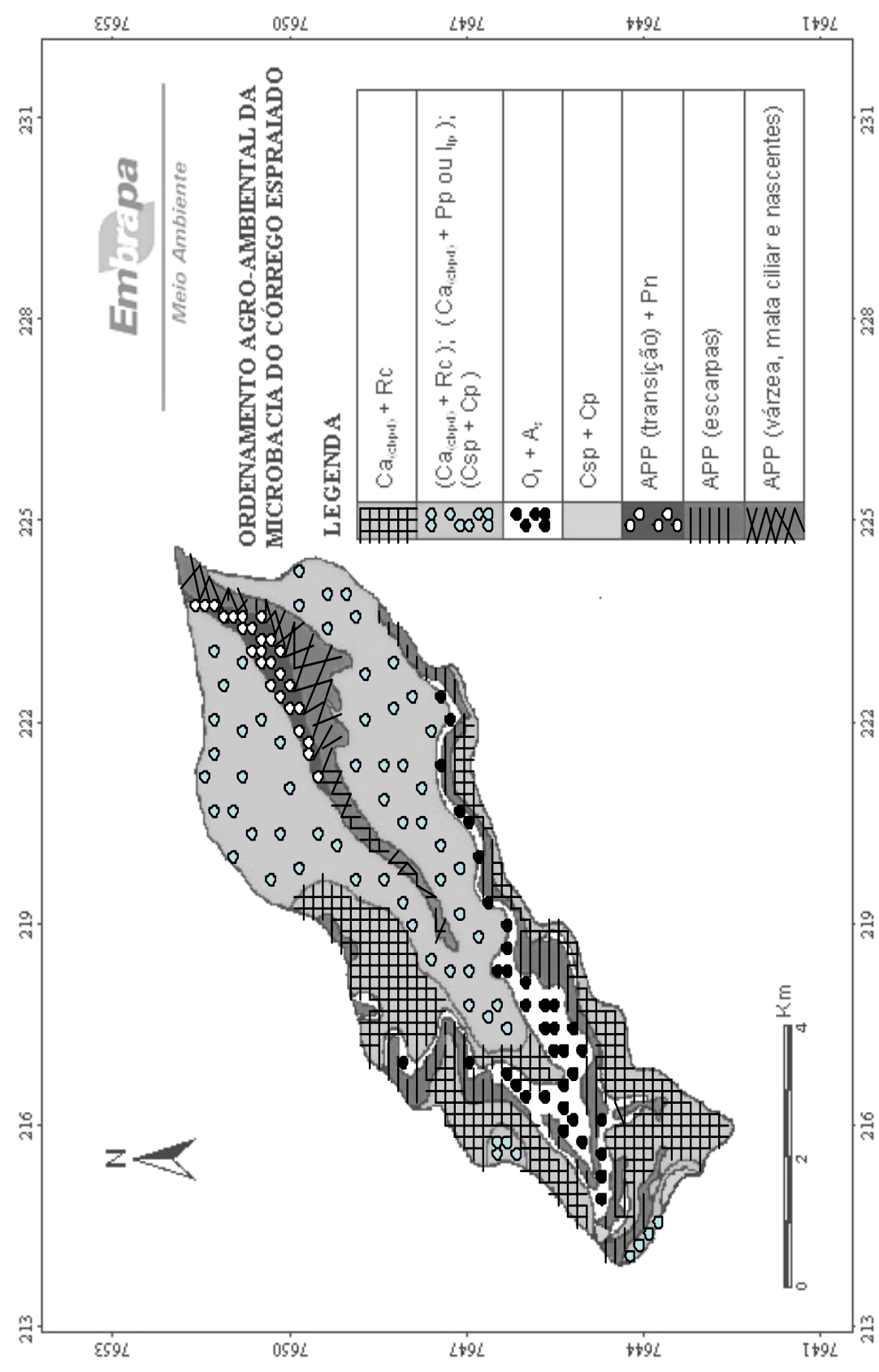




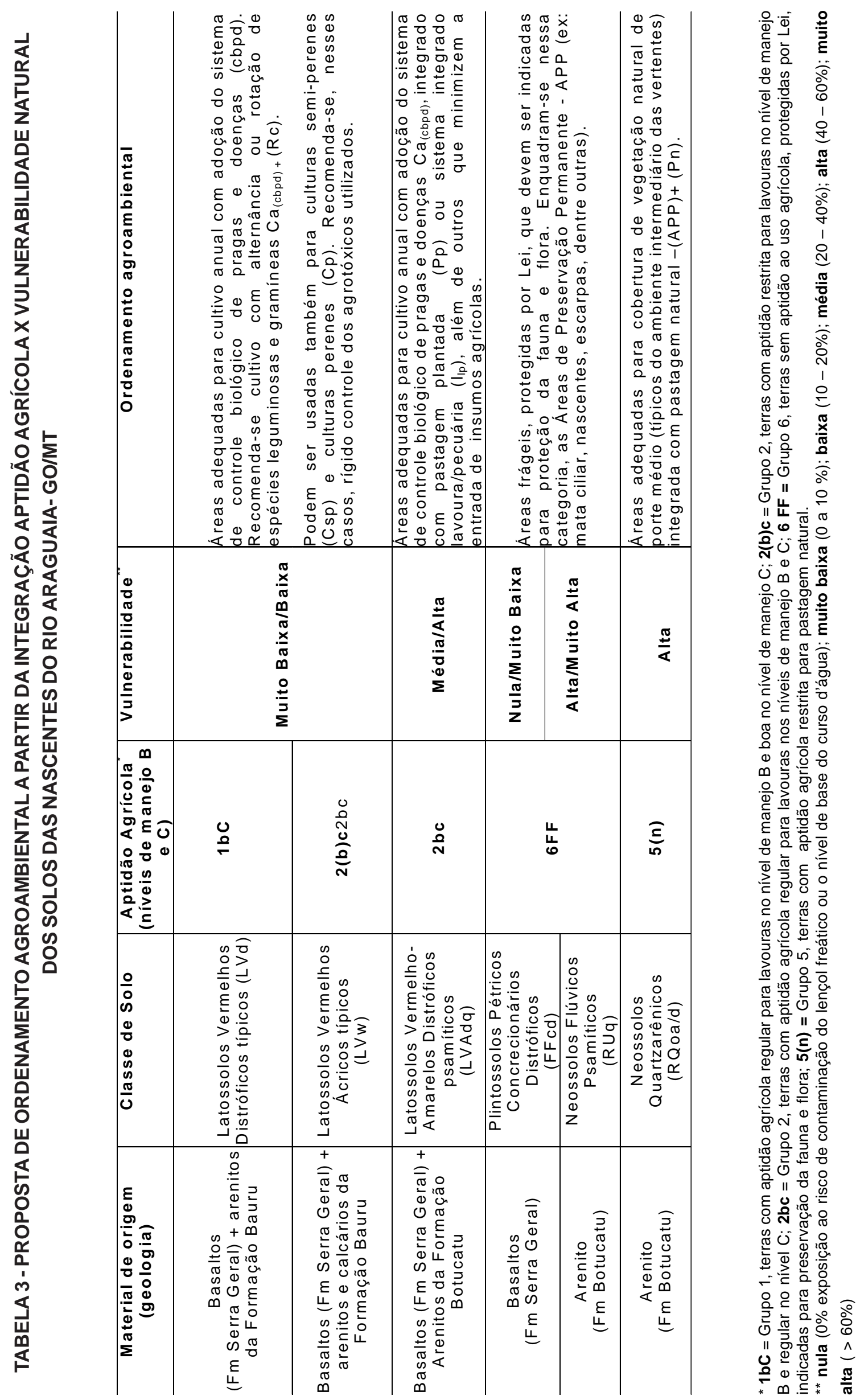




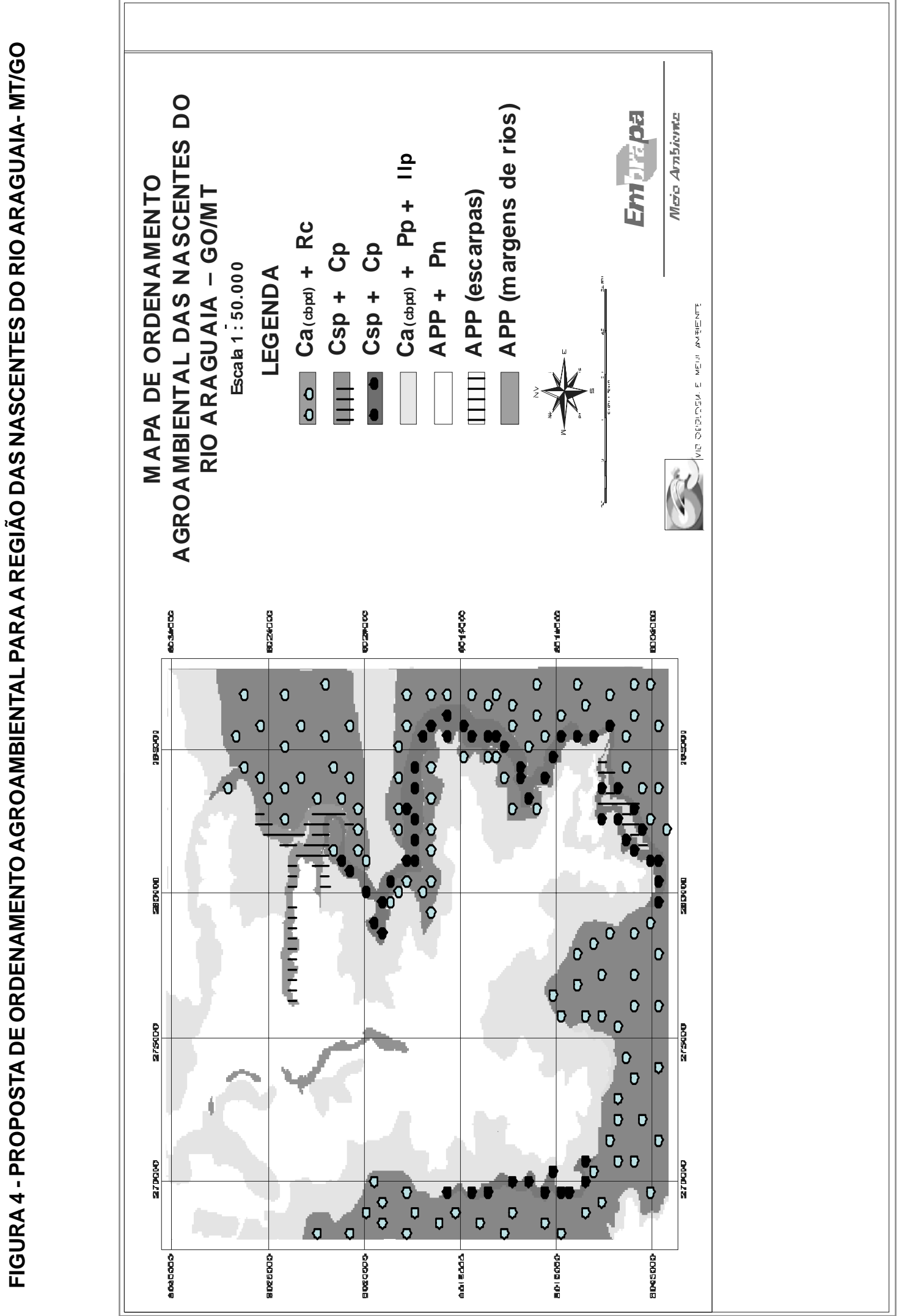




\section{CONCLUSÃO}

A proposta de Ordenamento agroambiental para as áreas de recarga direta do Aqüífero Guarani em território brasileiro, consideradas de alta vulnerabilidade natural, tem por objetivo subsidiar diversas ações voltadas para a sustentabilidade dessas áreas, também consideradas como frágeis sob o aspecto do uso e da ocupação.

A informação espacializada sobre os diversos usos agrícolas com eqüilíbrio ambiental, representada pelas Figuras 3 e 4, permite a compreensão de como usar racionalmente áreas de alta vulnerabilidade. Também serve de subsídio para a formulação de políticas públicas, incluindo Boas Práticas Agrícolas adequadas para cada domínio pedomorfoagroclimático nas áreas de recarga do Aqǘf́ero Guarani no Brasil. Nesse contexto, a presente proposta de ordenamento agroambiental visa também contribuir para o programa de Zoneamento Ecológico-Econômico do Ministério do Meio Ambiente, enquadrando-se no escopo de racionalização da ocupação do espaço territorial e do redirecionamento das atividades.

Espera-se que o presente trabalho possa, efetivamente, contribuir com o processo de gestão sustentável do Aqüífero Guarani, considerando as atividades agrícolas em suas áreas de recarga direta ou de afloramento no Brasil.

\section{ABSTRACT}

\section{AGRIENVIRONMENTAL ORDAINMENT OF THE RECHARGE AREAS OF THE GUARANY AQUIFER: CASE RESEARCH WORKS IN SÃO PAULO, GOIÁS AND MATO GROSSO STATES (BRAZIL)}

This work attempted to show that the organization of the land agriculture space in terms of agrienvironmental ordainment, constitutes an instrument of great importance in environmental researches, mainly in high natural vulnerability or high fragility areas, how are the recharge areas of the Guarany Aquifer. For this study, were adopted two representative areas of this aquifer, being the first named Espraiado watershed, located in Ribeirão Preto District, São Paulo State, into the Pedomorphoagriclimate Domain named Second Plateau Paulista, and the second area located in the source of Araguaia river on limit of the Goiás and Mato Grosso State into Pedomorphoagriclimate Domain named Araguaia Sources. The procedures consisted by integration of the areas basis, related to the geology, soil classification, natural vulnerability, groundwater risks contamination, soil use capacity, vegetable covering, according Brazilian Forest Code and Good Agricultural Practice (GAP).

KEY-WORDS: NATURAL VULNERABILITY; LAND USE POTENTIAL; GOOD AGRICULTURE PRACTICE; SUSTAINABLE USE; RECHARGE AREAS.

\section{REFERÊNCIAS}

1 ARAÚJO, L.M.; FRANÇA, A. B.; POTTER, P.E. Aqüífero gigante do Mercosul no Brasil, Argentina, Paraguai e Uruguai: mapas hidrogeológicos das formações Botucatu, Pirambóia, Rosário do Sul, Buena Vista, Misiones e Tacuarembó. Curitiba: UFPR/Petrobrás, 1995. 16 p. (9 mapas).

2 BOBELDIJK-PASTOROVA, I. Ontwikkeling en validatie van multimethoden voor prioritaire bestrijdingsmiddelen in water. Niewegein: Kiwa, 2000. (European Project SMT4-CT96-2142, v.2: HPLC-DAD Methode).

3 BRASIL. Ministério do Meio Ambiente. Secretaria de Assuntos Estratégicos da Presidência da República. Detalhamento da metodologia para execução do zoneamento ecológico-econômico pelos estados da Amazônia Legal. Brasília, 1997. 43 p.

4 CÂMARA, G.; SOUZA, R.C.M.; FREITAS, U.M.; GARRIDO, J.; MITSUO, F. SPRING: integrating remote sensing and GIS by object-oriented data modelling. Computers \& Graphics, v.20, p.395-403, 1996.

5 EASTMAN, J.R. IDRISI for windows. Worcester, Ma: Clark University, 2006.

6 EMBRAPA. Empresa Brasileira de Pesquisa Agropecuária. Manejo agro-ecológico das áreas de recarga do Aqüífero Guarani na região das nascentes do rio Araguaia, GO/MT. Jaguariúna, 2006a. 18 p. (Relatório parcial de projeto). 
7 EMBRAPA. Empresa Brasileira de Pesquisa Agropecuária. Proposta de ordenamento agroambiental das áreas de recarga do Aqüífero Guarani: estudo de casos nos estados de São Paulo e Rio Grande do Sul. Jaguariúna, 2006b. 10 p. (Relatório parcial de projeto).

8 EMBRAPA. Empresa Brasileira de Pesquisa Agropecuária. Uso agrícola das áreas de afloramento do Aqüífero Guarani e implicações na qualidade da água subterrânea. Jaguariúna, 2002. 32 p. (Relatório de projeto).

9 EMBRAPA. Empresa Brasileira de Pesquisa Agropecuária. Impacto ambiental e implicações sócio-econômicas da agricultura intensiva em água subterrânea. Jaguariúna, 1999. 43 p. (Relatório de projeto).

10 EMBRAPA. Empresa Brasileira de Pesquisa Agropecuária - Centro Nacional de Pesquisa de Solos. Manual de métodos de análise de solos. 2. ed. rev. atual. Rio de Janeiro, 1997. 212 p. (EMBRAPA-CNPS. Documentos, 1).

11 FERNANDES, C.E.M. Fundamentos de prospecção geofísica. Rio de Janeiro: Interciência, 1984. 190 p.

12 FIGUEIREDO, E. O.; ASSIS, L.D.; COSTA, J.; RECCO, R.D. Proposta metodológica para o zoneamento florestal pós-estratificado. Rio Branco: Embrapa Acre, 2000. 17 p. (Embrapa Acre. Documentos, 54).

13 FOSTER, S.; HIRATA, R. Determinação de risco de contaminação das águas subterrâneas. Um método baseado em dados existentes. São Paulo: Instituto Geológico, 1993. 92 p. (IG. Boletim, 10).

14 FRANQUIN, P.; FOREST, F. Des programmes d'évaluation et analyse frequentielles des termes du balance hydrique. L'agronomie Tropicale, v.32, n.1, p.1-22, 1984.

15 GOMES, M.A.F.; FILIZOLA, H.F.; SPADOTTO, C.A.; PEREIRA, A.S. Caracterização das áreas de afloramento do Aqüífero Guarani no Brasil - base para uma proposta de gestão sustentável. Jaguariúna: Embrapa Meio Ambiente, 2006. 20 p. (Embrapa Meio Ambiente. Documentos, 52).

16 GOMES, M.A.F.; SPADOTTO, C.A.; PESSOA, M.C.P.Y. Avaliação da vulnerabilidade natural do solo em áreas agrícolas: subsídio à avaliação do risco de contaminação do lençol freático por agroquímicos. Pesticidas: revista de ecotoxicologia e meio ambiente, v.12, p.169-179, 2002.

17 GOMES, M.A.F.; FILIZOLA, H.F.; SPADOTTO, C.A. Uso agrícola das áreas de recarga do Aqüífero Guarani e implicações na qualidade da água subterrânea. In: CONGRESSO BRASILEIRO DE SOJA E MERCOSOJA, 2., 2002, Londrina. Anais... Londrina: Embrapa Soja, 2002. p.36-42.

18 GOMES, M.A.F.; NEVES, M.C.; SPADOTTO, C. A.; LUIZ, A. J.B. Mapeamento expedito dos potenciais de infiltração e de escoamento superficial da água para os solos da microbacia do Córrego do Espraiado em Ribeirão Preto-SP. In: CONGRESSO LATINO-AMERICANO DE CIÊNCIA DO SOLO, 13., 1996, Águas de Lindóia. Anais... Piracicaba: SBCSI ESALQ, 1996. 4.p. (CD-ROM).

19 GUSTAFSON, D.I. Groundwater ubiquity score: a simple method for assessing pesticide leachability. Environmental Toxicology and Chemistry, v.8, p.339-357, 1989.

20 IPT. Instituto de Pesquisas Tecnológicas do Estado de São Paulo. Caracterização do potencial de contaminação das águas subterrâneas por agroquímicos: hidrogeologia da microbacia. São Paulo, 1994. 33 p. (Relatório n. 32 309).

21 KRAMER, P.J. Plant and soil water relationships: a modern synthesis. New York: McGraw-Hill, 1969. 482 p.

22 LESPCH, I.F.; BELLINAZI JUNIOR, R.; BERTOLINI, D.; ESPINDOLA, C.R. Manual para levantamento utilitário do meio físico e classificação de terras no sistema de capacidade de uso. 4. ed. 2. imp. revisada. Campinas: SBCS, 1991. 175 p.

23 LYDON, J.; ENGELKE, B.F.; HELLING, C.S. Simplified high-performance liquid chromatography method for the simultaneous analysis of tebuthiuron and hexazinone. Journal of Chromatography A, v.536, p.223-228, 1991.

24 MATSUMOTO, E.Y. AutoCAD 2006: guia prático - 2D \& 3D. São Paulo: Érica, 2005. 374 p.

25 MIKLÓS, A.A.W.; GOMES, M. A. F. Levantamento semidetalhado dos solos da bacia hidrográfica do Córrego do Espraiado, Ribeirão Preto- SP. São Paulo, 1996. 48 p. (Relatório de Consultoria).

26 NOFZIGER, D.L.; HORNSBY, A.G. CMLS-94 - Chemical Movement in Layered Soils. Oklahoma: University of Florida, Department of Agronomy, 1994. $76 \mathrm{p}$.

27 PEREIRA, L.C. Aptidão agrícola das terras e sensibilidade ambiental: proposta metodológica. Campinas, 2002. 122 p. Tese (Doutorado em Planejamento e Desenvolvimento Rural Sustentável) - Faculdade de Engenharia Agrícola, Universidade Estadual de Campinas.

28 RAMALHO FILHO, A.; PEREIRA, E.G.; BEEK, K.J. Sistema de avaliação da aptidão agrícola das terras. Brasília: SUPLAN/Embrapa/SNLCS, 1995. 65 p. 
29 RIBEIRO, M.A. Zoneamento ambiental. Belo Horizonte: IGA/CETEC-MG, 1994. 21 p.

30 ROCHA, G.A. Mega reservatório de água subterrânea do Cone Sul: bases para uma política de desenvolvimento e gestão. Curitiba: UFPR/IDRC, 1996. 25 p.

31 SÃO PAULO. Secretaria de Energia e Saneamento. Departamento de Águas e Energia Elétrica. Controle de erosão: bases conceituais e técnicas; diretrizes para o planejamento urbano e regional; orientações para o controle de voçorocas urbanas. São Paulo: DAEE/IPT, 1989. 92 p. 